\section{$\underset{\substack{\text { hommes } \\ \text { \& migrations }}}{ }$}

\section{Hommes \& migrations}

Revue française de référence sur les dynamiques

migratoires

1302 | 2013

Le Japon, pays d'immigration?

\title{
Gérald Bloncourt, Les Portugais
}

\section{Marie Poinsot et Anne Volery}

\section{QpenEdition \\ Journals}

\section{Édition électronique}

URL : http://journals.openedition.org/hommesmigrations/2499

DOI : 10.4000/hommesmigrations.2499

ISSN : 2262-3353

\section{Éditeur}

Musée national de l'histoire de l'immigration

\section{Édition imprimée}

Date de publication : 1 avril 2013

Pagination : 152-153

ISBN : 978-2-919040-22-3

ISSN : $1142-852 X$

\section{Référence électronique}

Marie Poinsot et Anne Volery, « Gérald Bloncourt, Les Portugais », Hommes \& migrations [En ligne], 1302 | 2013, mis en ligne le 12 septembre 2013, consulté le 24 septembre 2020. URL : http:// journals.openedition.org/hommesmigrations/2499; DOl : https://doi.org/10.4000/ hommesmigrations.2499 


\title{
ENTRETIEN
}

\section{GÉRALD BLONCOURT LES PORTUGAIS}

\author{
Entretien réalisé par MARIE POINSOT ET ANNE VOLERY, \\ chargée de l'édition multimédia, CNHI
}

$\mathrm{N}$ é en Haïti, contraint à l'exil, Gérald Bloncourt arrive en France en 1946. II y débute sa carrière de photojournaliste en 1950, à L'Humanité. Après un passage à L'Avant-garde puis à La Vie ouvrière, il devient reporter indépendant à partir des années 1960. Très vite, c'est le monde du travail qui l'intéresse : dénoncer la misère, montrer le monde ouvrier, le travail, les usines... Sur les chantiers, il croise les travailleurs immigrés et notamment les Portugais. Cette rencontre est l'occasion pour lui de montrer une réalité complexe. De 1954 à 1974, il les photographie au travail, mais donne aussi à voir différentes facettes de leur vie de migrants : les conditions de logement, celles du voyage, le pays qu'ils ont quitté... C'est ce travail qui est montré à la Cité nationale de l'histoire de l'immigration dans le cadre de l'exposition Pour une vie meilleure.

Hommes \& Migrations : Pourquoi avez-vous photographié le bidonville de Champigny où habitaient des travailleurs portugais et leurs familles ? Comment avez-vous approché cette population?

Gérald Bloncourt : J'ai photographié beaucoup d'Algériens, de Yougoslaves, de Portugais en tant que photographe indépendant, puisque j'allais dans les usines et suivais les mouvements sociaux où ces travailleurs étaient très présents. J'ai une histoire plus particulière avec les Portugais car j'ai une certaine fascination pour le
Portugal : lorsque j'étais gamin, j'ai découvert le "pays des grands découvreurs", comme Vasco de Gama. J'étais fasciné par cette histoire et j'ai beaucoup lu sur le sujet, tout comme à propos des corsaires et des pirates dans la Caraïbe. C'étaient un peu mes lointains ancêtres, et je me disais qu'il fallait que j'aille au Portugal un jour. Puis je suis tombé sur des Portugais : j'ai vu des personnes sérieuses, des ouvriers qui avaient une façon particulière de nettoyer et de tenir leurs outils, leur fils à plomb. Cela m'intéressait, car je suis aussi un bricoleur, et ces gens m'impressionnaient. Ils étaient pour moi les descendants des grands découvreurs. J'étais attiré par eux et j'ai voulu voir comment et où ils vivaient. Or, dans la région parisienne, beaucoup d'entre eux se retrouvaient dans les bidonvilles. Je me suis donc rendu un soir dans le bidonville de Champigny. Je voulais prendre des photos "dramatiques", prises au moment du retour des travailleurs. Pendant que je prenais ces photos, quatre types m'ont entouré, ils avaient un couteau. Ils m'ont interpellé et m'ont entraîné dans une cabane, très propre malgré la boue qu'il y avait partout, et ils ont appelé leur chef. Heureusement, celui-ci m'a reconnu : c'était un ouvrier de chez Renault que je connaissais bien.

On s'est donné l'accolade et ils ont soulevé des planches de la cabane qui cachaient des bouteilles de porto. On a bu ensemble et c'est comme cela que j'ai été admis dans le bidonville. Je pouvais 


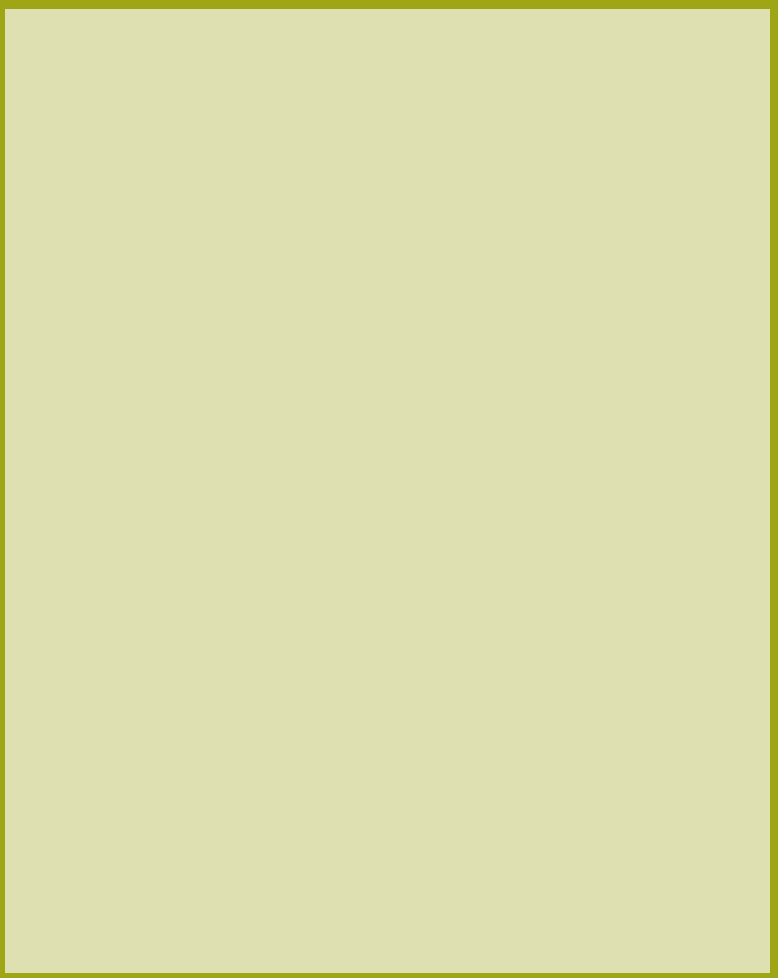

Ils viennent de descendre du car qui les a amenés du Portugal et attendent, angoissés, des amis qui doivent venir les chercher pour les héberger dans la capitale, Paris 1963 (c) Gérald Bloncourt

venir quand je voulais, je prenais des photos et je suis devenu copain avec des résistants qui avaient fui la dictature de Salazar.

H\&M : Vous n'avez pas seulement photographié la vie quotidienne des immigrés portugais dans ce bidonville, vous avez aussi voulu "remonter" la filière migratoire et montrer le passage des frontières et les villages dont étaient originaires ces populations. Comment avez-vous fait ?

G. B. : Les habitants du bidonville m'ont parlé du Portugal et cela m'a beaucoup intéressé,j'ai voulu yaller : je m'y suis rendu en avion et j'ai fait ensuite toute la route de l'immigration, en passant par Porto et par la montagne de Chavez. Je suis arrivé dans des villages où tous les hommes étaient partis. Il y avait des personnes prudentes, craintives, mais peu à peu on a pu parler : certains habitants et certains migrants connaissaient le français et j'ai pu me débrouiller, même si je ne parlais pas un mot de portugais J'ai passé quelque temps avec eux. C'était très dur, en plein hiver. Je me souviens qu'ils ne voulaient pas que je les prenne en photo. Les images que vous connaissez, quej'ai pu rapporter,je les ai prises à la sauvette,car je me suis dit qu'il fallait garder ces instants.

On voyait des personnes qui partaient avec toute leur maison sur leur dos pour rejoindre Paris, on assistait à des retrouvailles... En fait, je me suis attaché à ces personnes, et j'ai pu, finalement par hasard, réaliser des photos de travailleurs portugais, des bidonvilles, du passage des Pyrénées, de la révolution des $\mathbb{E}$ illets.

H\&M : En 1974, vous êtes à Lisbonne au lendemain de la chute de la dictature. Qu'est-ce qui vous a le plus marqué pendant ces jours de liesse populaire?

G. B. : J'ai été prévenu de la révolution et je me suis rendu au Portugal. Dans le même avion que moi, il y avait Alvaro Cunhal qui rentrait avec des amis et qui chantait en battant du pied au point que l'hôtesse est venue leur dire d'arrêter car ils allaient faire tomber l'avion.

À l'arrivée, il y avait des œillets partout et j'ai passé deux nuits et trois jours sans dormir, en roupillant ici et là car tous les hôtels étaient pris. Il y avait des photographes du monde entier. J'ai vu les retrouvailles de personnes qui avaient passé dix ans en prison, et une joie dans les rues, une liesse, que l'on ne peut pas décrire. 